\title{
PLANT PERFORMANCE ACROSS LATITUDE: THE ROLE OF PLASTICITY AND LOCAL ADAPTATION IN AN AQUATIC PLANT
}

\author{
L. Santamaría, ${ }^{1,5}$ J. Figuerola,${ }^{2}$ J. J. Pilon,${ }^{1}$ M. Mjelde,${ }^{3}$ A. J. Green, ${ }^{2}$ T. de Boer,${ }^{1}$ \\ R. A. KING, ${ }^{4}$ AND R. J. GORnALL ${ }^{4}$ \\ ${ }^{1}$ Netherlands Institute of Ecology (NIOO-KNAW), Center for Limnology, P.O. Box 1299, 3600 BG Maarssen, \\ The Netherlands \\ ${ }^{2}$ Doñana Biological Station (CSIC), Department of Applied Biology, Avda Maria Luisa S-N, E-41013 Seville, Spain \\ ${ }^{3}$ Norwegian Institute for Water Research (NIVA), P.O. Box 173 Kjelsas, N-0411 Oslo, Norway \\ ${ }^{4}$ Department of Biology, University of Leicester, University Road, Leicester LE1 7RH United Kingdom
}

Abstract. Geographic variation can lead to the evolution of different local varieties within a given species, therefore influencing its distribution and genetic structure. We investigated the contribution of plasticity and local adaptation to the performance of a common aquatic plant (Potamogeton pectinatus) in contrasting climates, using reciprocal transplants at three experimental sites across a latitudinal cline in Europe. Plants from 54 genets, originally collected from 14 populations situated within four climatic regions (subarctic, cold temperate, mild temperate, and mediterranean) were grown in three different localities within three of these regions (cold temperate, Norway; mild temperate, The Netherlands; mediterranean, Spain). Tuber production was highest for the mild-temperate genets, irrespective of locality where the genets were grown. Selection coefficients indicated that populations at the European center of the species distribution perform better than all other populations, at all sites. However, marginal populations showed changes in life-history traits, such as compressed life cycles in the north and true perenniality in the south, that may allow them to perform better locally, at the limits of their distribution range. Our results thus suggest that local adaptation may overlap spatially with center-periphery gradients in performance caused by genetic factors (such as genetic drift and inbreeding in range-marginal populations).

Key words: climate; clonal reproduction; distribution; latitude; local adaptation; plasticity; Potamogeton pectinatus; reciprocal transplant; shoot morphology; survival; vegetative growth.

\section{INTRODUCTION}

Common plant species with wide distributions may perform well in a wide range of environmental conditions (Joshi et al. 2001). However, the capacity of individual genotypes to perform well across the full range of conditions is often limited (De Witt et al. 1998). Widespread terrestrial species are often characterized by both phenotypic plasticity and high levels of genetic variation (Bradshaw 1984) and by local specialization to particular environmental conditions (Van Tienderen 1990, Joshi et al. 2001). In contrast, aquatic plant species, many of which are also widespread, have often been shown to have limited genetic variation, suggesting the common occurrence of general-purpose genotypes among them (Barrett et al. 1993, Santamaría 2002). Generalpurpose genotypes are able to maintain a high fitness over broad ranges of environmental conditions, through compensatory plastic responses in morphology, physiology, and/or phenology (adaptive plasticity; Schlichting 1986, Dudley and Schmitt 1995).

Manuscript received 18 July 2002; revised 14 January 2003; accepted 20 January 2003. Corresponding Editor: M. Loreau.

${ }^{5}$ Present address: Mediterranean Institute for Advanced Studies (IMEDEA, CSIC-UIB), Department of Terrestrial Ecology, C/ Miguel Marquès 21, 07190 Esporles, Mallorca (Illes Baleares), Spain. E-mail: viealsg0@uib.es
One of the main sources of environmental variation, particularly at continental scales, is climate. This is reflected in worldwide vegetation zones, which follow the latitudinal pattern of prevailing environmental conditions (e.g., Walter 1973); and in global patterns of plant distribution, which are largely explained by species-specific responses to temperature and precipitation (e.g., Woodward and Williams 1987, Woodward 1990). Solar irradiance and temperature decrease with increasing latitude, while summer photoperiod increases. Since these variables are known to influence many aspects of plant life (Berry and Raison 1981, Björkman 1981, Salisbury 1981), widely distributed plant species may be expected to show phenotypic variability across latitude. Genetically based latitudinal variation in phenology (Potvin 1986, Weber and Schmid 1998), growth (Chapin and Chapin 1981, Sawada et al. 1994, Li et al. 1998), and sexual reproduction (Aizen and Woodcock 1992, Winn and Gross 1993) has been reported among terrestrial species. In general, ecotypes originating from higher latitudes show relatively small statures, early flowering, and decreased fecundity due to lower growth rates or short developmental cycles (Chapin and Chapin 1981, Potvin 1986, Winn and Gross 1993, Li et al. 1998). In the context of aquatic plants, while some information is available for sea- 
grasses (Philipps et al. 1983) and marine macroalgae (Orfanidis and Breeman 1999), latitudinal adaptations in freshwater angiosperms have received little attention. Because the latter are among the most widely distributed plants (Santamaría 2002) and represent a key component of shallow and littoral aquatic ecosystems (Carpenter and Lodge 1986), we wanted to determine the extent to which their broad distributions are related to local specialization of populations from different climatic regions.

The contribution of environmental and genetic variation to phenotypic variability and performance can be assessed using reciprocal-transplant experiments, where significant home vs. away differentials are assumed to reflect local adaptation (e.g., Joshi et al. 2001). Reciprocal transplants have typically been performed over small scales and with terrestrial species (Bradshaw 1984, Schmid 1985, Linhart and Grant 1996), often revealing the existence of local adaptation (e.g., McGraw and Antonovics 1983, Nagy and Rice 1997). Population differentiation in morphological and physiological traits has also been reported for a few aquatic species, typically involving laboratory experiments rather than outdoor transplants (e.g., Koch and Dawes 1991, Barrett et al. 1993). Recently, Joshi et al. (2001) extended the replant-transplant approach to a European scale, aiming to correlate the difference in home vs. away phenotypic performance with climatic distances between sites. They found the overall performance of three grassland species to decline with increasing transplanting distance, being highest for home replants (Joshi et al. 2001). However, climatic distance was not correlated with selection indices and only accounted for $18 \%$ of the variation related to geographic distance, suggesting that the observed pattern of variation could be caused by factors other than climate (such as biotic influences). Since Joshi et al. (2001) performed their experiment directly in local field sites, they were not able to evaluate the contribution of local (e.g., edaphic or biotic) conditions vs. climatic environmental variation to the observed patterns of local specialization. In this study, we attempted to minimize local variation by standardizing most of the environmental variables, e.g., soil characteristics and water chemistry, that are not related to climatic conditions, i.e., temperature, irradiance, and photoperiod. Furthermore, we attempted to evaluate the relative contribution of plasticity to the observed patterns of phenotypic variation and to remove the influence of environmentally induced maternal effects (Rossiter 1998) by multiplying all sampled genotypes under standardized conditions during a complete growing season prior to transplanting their clonal propagules to all our experimental sites.

\section{Materials and Methods Study species}

Potamogeton pectinatus L. (fennel pondweed) is a submerged angiosperm with a pseudoannual life cycle and a cosmopolitan distribution (Hultén and Fries 1986). Plants grow during spring-summer and survive the winter by means of subterranean tubers (specialized asexual propagules). Under mild climatic conditions, $P$. pectinatus may grow as a perennial (Yeo 1965). Annual seed production varies greatly and its contribution to yearly population recruitment is generally considered to be minimal in temperate regions (e.g., Van Wijk 1989). Instead, seeds might be important for dispersal and establishment after disturbances (Van Wijk 1989). Given the limited importance and reliability of short-term sexual fecundity estimates, we considered that asexual population growth rate $(r)$, a surrogate of genet survivorship, represents a better fitness correlate than fecundity (see also Crone 2001).

\section{Reciprocal transplant experiment}

In summer-autumn 1998 and spring 1999, tubers and/or rhizome fragments were collected from at least four spaced $(>10 \mathrm{~m})$ individuals at each of 14 localities in Europe and North Africa, grouped within five discrete latitudinal ranges taken to represent different climatic regions (Fig. 1, Appendix A). In summer 1999, we grew a single tuber or rhizome fragment from each sampled individual, i.e., one putative genet, under outdoor, common-garden conditions in Heteren (The Netherlands), in order to obtain clonal propagules (tubers). The mediterranean populations failed to produce tubers under such circumstances, since they are probably truly perennial; hence we kept the plants growing during the following winter in indoor aquaria and utilized rhizome fragments as propagules. Growing the plants indoors during the winter was also necessary for a few Swedish genets, due to their low tuber production. For such genets, both tubers (from the previous autumn) and rhizome fragments (from living plants) were used as propagules in the transplant experiment. Out of five clonal fragments collected from Loch Gelly (Scotland), only three clonal lines became established during the propagation phase; hence, we were only able to use three genets for this population.

Potamogeton pectinatus hybridizes with closely related species of the subgenus Coleogeton. In northern regions (United Kingdom, Denmark, Norway, Sweden, and Russia), at least two of the hybrids, viz. $P$. $\times$ suecicus $(P$. pectinatus $\times P$. filiformis) and $P . \times$ bottnicus ( $P$. pectinatus $\times P$. vaginatus $)$, are very difficult to discriminate from $P$. pectinatus on the basis of morphological traits (Preston et al. 1998, 1999). For this reason, the identity of the collected genets was confirmed by means of RFLP analysis of nuclear and chloroplast DNA extracted from freshly grown material, following the methods described by King et al. (2001). In addition, ISSR (intersimple sequence repeat) "fingerprint" data were used to discriminate between different $P$. pectinatus genets; i.e., to ensure that the putative genets selected for the experiment did indeed represent different genotypes (see Appendix B for de- 


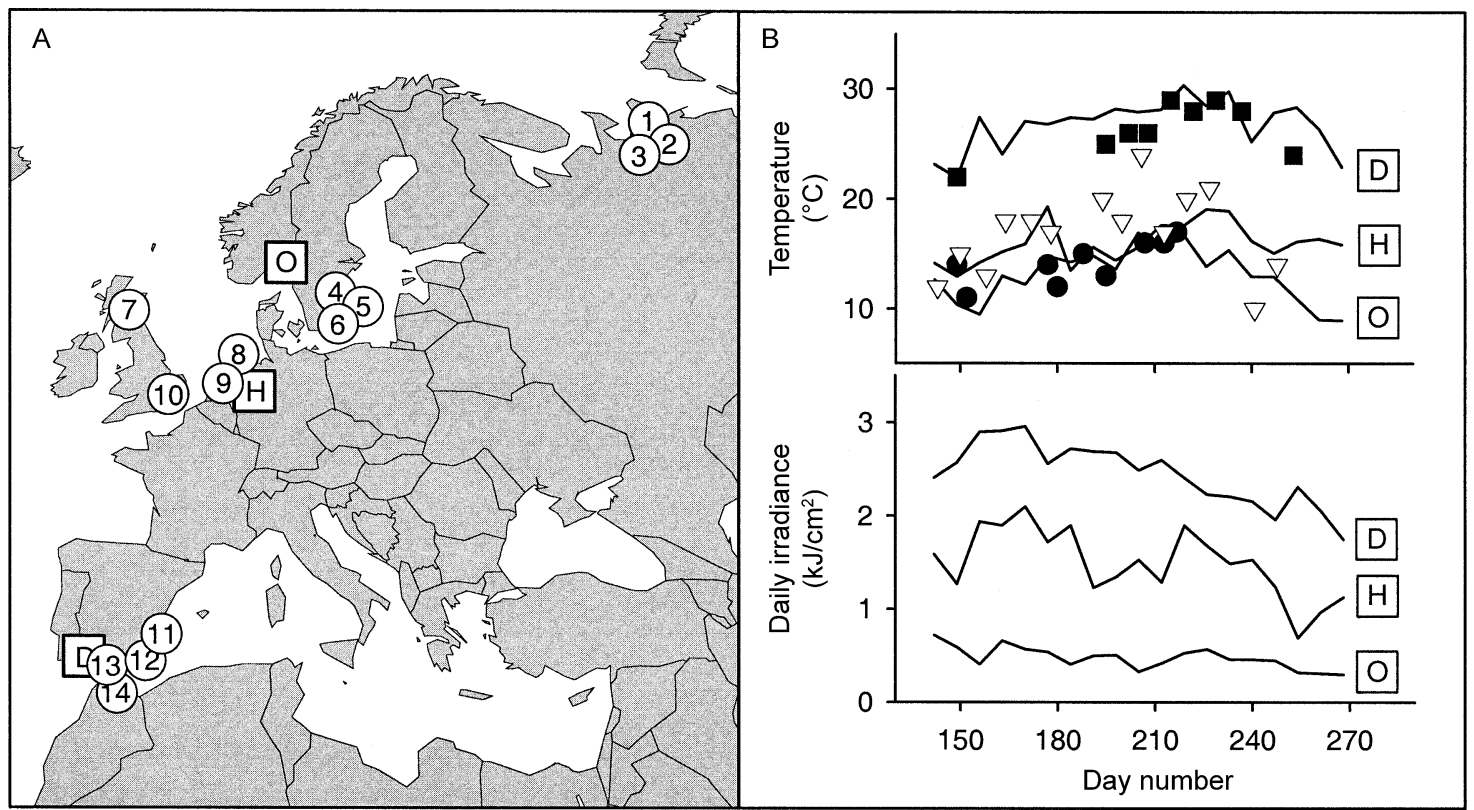

FIG. 1. (A) Geographic origin of the P. pectinatus populations used in the transplant experiment (circles with population numbers) and location of the three experimental sites where they were grown (squares). In the squares "O" refers to Oslo (Norway), " $\mathrm{H}$ " to Heteren (The Netherlands), and " $\mathrm{D}$ " to Doñana (Spain). Population numbers are used to give entry to geographic characteristics of populations in Appendix A. (B) Weekly averages of mean air temperature (lines), mean water temperatures (symbols), and daily irradiance at the three experimental sites for the period between 15 May and 24 September 2000.

tails). A high proportion of the clones sampled from one of the Russian populations (Srednii Shar) were identified as hybrids; hence, we were only able to use three $P$. pectinatus genets for this population.

For the transplant experiment (summer 2000), we grew plants from the 54 clonal lines at three distant localities, situated at different latitudes and having contrasting climates (Doñana, southwest Spain; Heteren, The Netherlands; and Oslo, southeast Norway; Fig. 1, Appendix A). The provenance of the genets corresponded to the three experimental localities, together with Scotland (situated between two of the experimental sites; Fig. 1) and northern Russia (situated in the northern range limit of the species). The design was not fully balanced, owing to the shortage of tubers from a few genets: although we aimed to use five replicates per genet and growing site, a total of 613 plants was finally grown (204 in Norway, 207 in The Netherlands, and 202 in Spain), corresponding to a factorial combination of 3 sites $\times 54$ genets using an average of 3.8 replicates. At each experimental locality, plants were cultivated under common-garden conditions (Appendix C).

Plant propagules were planted in mid-May 2000, by inserting them carefully through the first $2 \mathrm{~cm}$ of washed aquarium sand into the clay-sand sediment mixture. Plants were cultivated until the end of September, when they were harvested by washing off the sediment using pressurized water and a 2-mm sieve. In the laboratory, we measured the length of the longest shoot and the number of ramets per plant, and separated the aboveground (shoots) and belowground (roots + rhizomes) fractions to measure their dry mass (after 24 $\mathrm{h}$ at $70^{\circ} \mathrm{C}$ ). Tubers were weighed individually (fresh mass) and a random subsample was used for dry mass determinations (as above, $N=240$ ). Based on this subsample, the dry mass of the remaining tubers was estimated from linear regressions relating dry mass to fresh mass (separately for each experimental locality and region of genet origin; $R^{2}$ always above 0.95 ).

In pseudoannual plants, asexual rates of population growth $(r)$ are best estimated as the product of asexual fecundity $\left(f_{\mathrm{a}}\right)$, calculated here as the average number of tubers per genet and recorded separately at each experimental site, and survival probability $(p)$, calculated here as the proportion of plants that produced at least one ramet or one viable tuber, for each genet and experimental site. Thus $r=p \times f_{\mathrm{a}}$. We then used $r$ as a measure of plant performance or fitness, and calculated selection coefficients for each genet $i$ relative to the best-performing genet at each particular experimental site as $s_{i}=1-\left(r_{i} / r_{\text {max }}\right)$. Thus $s_{i}$ ranges from 0 (for the most successful genet at each site) to 1 (indicating complete selection against a given genet). This procedure may underestimate the performance of perennial plants growing in mild climates, since genets that produced no tubers have a $s_{i}=1$. For this reason, fitness estimates of plants that produced no tubers but did not senesce by the end of the experiments, i.e., the mediterranean genets growing in Spain, were also calculated using asexual rates of population growth based 
TABLE 1. Selection coefficients (i.e., performance [fitness] of each genet relative to the best-performing genet at a given experimental site, averaged for each locality of origin of the genets).

\begin{tabular}{llccc}
\hline \hline \multirow{2}{*}{ Region of origin } & \multicolumn{4}{c}{ Experimental site } \\
\cline { 2 - 4 } & \multicolumn{1}{c}{ Norway } & The Netherlands & Spain & $N$ \\
\hline Russia & $\mathbf{0 . 5 2 3}(0.313,0.732)^{\mathrm{a}}$ & $0.666(0.550,0.782)^{\mathrm{ab}}$ & $0.612(0.486,0.739)^{\mathrm{ab}}$ & 12 \\
Sweden & $\mathbf{0 . 9 8 7}(0.960,1.015)^{\mathrm{b}}$ & $0.889(0.812,0.966)^{\mathrm{bc}}$ & $0.908(0.864,0.952)^{\mathrm{c}}$ & 12 \\
Scotland & $0.848(0.685,1.011)^{\mathrm{ab}}$ & $\mathbf{0 . 3 6 0}(0.154,0.567)^{\mathrm{a}}$ & $0.161(-0.354,0.675)^{\mathrm{a}}$ & 3 \\
The Netherlands/United Kingdom & $0.732(0.570,0.895)^{\mathrm{ab}}$ & $\mathbf{0 . 4 6 4}(0.317,0.610)^{\mathrm{a}}$ & $0.455(0.319,0.591)^{\mathrm{a}}$ & 12 \\
Spain/Morocco & $1^{\mathrm{b}}$ & $0.997(0.994,1.001)^{\mathrm{c}}$ & $\mathbf{0 . 9 0 2}(0.851,0.952)^{\mathrm{c}}$ & 16 \\
Mean & $0.826(0.753,0.899)$ & $0.746(0.673,0.819)$ & $0.698(0.623,0.773)$ & 55 \\
\hline
\end{tabular}

Notes: The selection coefficient values range from 0 (for the most successful genet at each site) to 1 (indicating complete selection against a given genet). Values in parentheses indicate $95 \%$ confidence intervals. Different superscript letters indicate significant differences between regions of origin for a given experimental site, with lettering order indicating increasing selection coefficients (Scheffé post hoc tests, $P<0.05$ ). Bold type indicates "home." $N=$ number of genets.

on the average number of ramets per plant, i.e., the number of potentially independent clonal individuals, instead of the number of tubers. Fitness estimates using tubers or tubers + ramets were almost identical; hence, we only report on the latter.

\section{Statistical analysis}

All variables measured (total biomass, vegetative biomass, and tuber production; number of tubers and tuber size; shoot length, shoot-root ratio, and number of ramets; and clonal survival) and fitness estimates were analyzed by means of hierarchical, mixed-models ANOVAs (Appendix D), performed in the General Linear Models module of Statistica 5.5 (Statsoft 1999). The main effects attributable to environment ("site") and genetics (decomposed in "region," "population," and "genet") were interpreted to represent the general superiority of plants growing at, or originating from a particular site, while interaction effects indicate that different strains respond differently at different sites (similar to Joshi et al. 2001). In the site $\times$ region matrix (Table 1), a home effect is represented by values found on the diagonal in bold and an increasing distance effect is reflected by values further away from the diagonal in bold.

\section{RESUlts}

During the experimental period (May-September 2000), pronounced climatic differences existed between the experimental sites in Norway, The Netherlands, and Spain. P. pectinatus genets that were grown at higher latitudes experienced lower air and water temperatures, lower levels of daily irradiance, and longer photoperiods than those grown in the south (Fig. 1).

Environmental (site) and genetic (region, population, and genet) effects, as well as their interactions on lifehistory characters were statistically significant in most cases (Appendix E). Environmentally induced variation occurred in all variables measured, reflecting an increase in performance with decreasing latitude (Fig. 2). Genetic effects occurred mostly at regional level, with almost no significant differences among populations and few among genets. Most genetic $\times$ environmental variation was ex- plained by region $\times$ site interactions, with few significant interactions at population and genet levels. Propagule size and type had limited effects on plant growth, affecting significantly only a few variables.

Biomass yield (total, vegetative, and tubers) increased significantly when the plants were grown at sites of decreasing latitude (ANOVA, $P<10^{-10}$ for all three variables; Fig. 2A and D). Total biomass yield and tuber production were higher for midlatitude genets (Netherlands/England and Scotland) and lower for northern (Swedish/Russian) and southern (Spanish/Moroccan) genets (ANOVA, factor region, $P<0.001$ for both variables). Vegetative biomass followed the same trend, except for the mediterranean genets grown in Spain, which had the highest biomass yield observed in the experiment (ANOVA, $P<10^{-8}$ for region, $P=0.023$ for site $\times$ region, Fig. $2 \mathrm{~A}$ ). Even in their "native" experimental site, however, most clonal replicates of the mediterranean genets failed to produce tubers (Fig. 2D).

Swedish genets, and those mediterranean genets that tuberized, produced fewer but larger tubers (ANOVA, factor region, $P<0.0006$; Fig. $2 \mathrm{E}$ and F) and showed also the largest plasticity in tuber size, which was significantly reduced when the plants grew in "less favorable" experimental sites (e.g., in Norway for the Swedish genets) (ANOVA, site $\times$ region, $P<10^{-9}$; Fig. 2F).

Shoot length increased with decreasing latitude of origin, being maximal for the mediterranean genets (ANOVA, factor region, $P=0.0048$ ). It also tended to decrease from southern to northern experimental sites (ANOVA, $P<10^{-5}$; Fig. 2C). The relative differences in phenotype among experimental sites varied according to the region of origin. For the mediterranean genets, there were large differences in shoot length between the experimental site in Norway and those in the Netherlands and Spain, which did not differ significantly from each other (Scheffé post hoc tests, $P<10^{-5}, P<10^{-8}$, and $P=0.99$, respectively). For the Russian genets, the pattern was reversed: large differences occurred between the experimental site in Spain and those in The Netherlands and Norway, which were not significantly different (Scheffé post hoc tests, $P=0.037, P=0.0001$, and $P=0.99$, respectively). For the Dutch/English and 

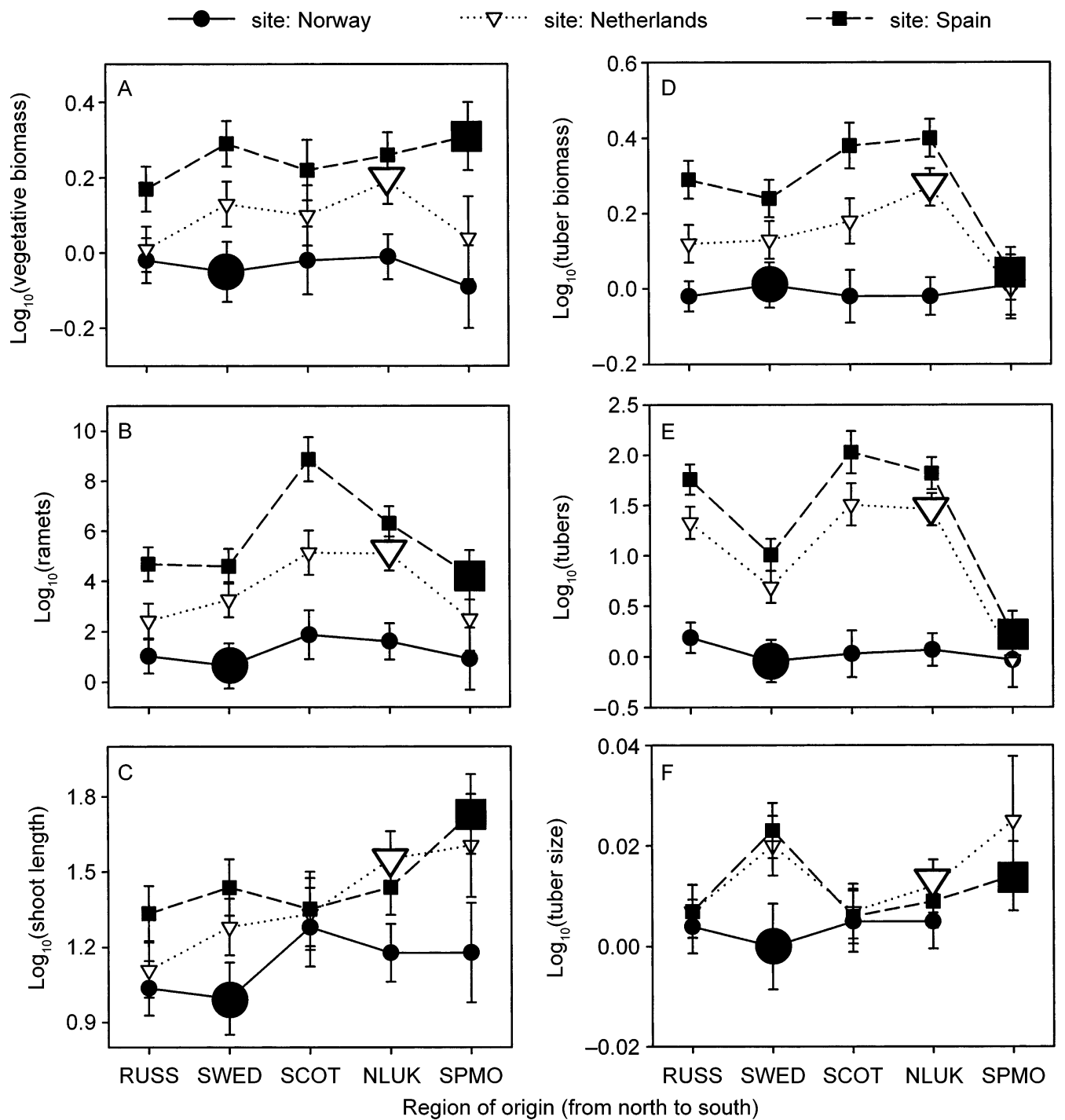

FIG. 2. (A) Vegetative biomass (measured in g dry mass +1 ), (B) number of ramets (measured in no. +1 ), (C) shoot length (measured in $\mathrm{cm}+1$ ), (D) tuber biomass (measured in g dry mass +1$)$, (E) number of tubers (measured in no. + 1 ), and $(\mathrm{F})$ tuber size (measured in g mass +1 ) for $P$. pectinatus genets originally collected at five different regions across Europe (RUSS, northern Russia; SWED, Sweden; SCOT, Scotland; NLUK, The Netherlands and United Kingdom; SPMO, Spain and Morocco) and grown under common garden conditions at three experimental sites (Norway, The Netherlands, and Spain). Larger symbols indicate populations growing at their home site (i.e., region $=$ site). Shown are log-transformed means \pm 1 SE. Means were computed at the covariate's mean $\left(\log _{10}\right.$ tuber mass, $0.017 ; \log _{10}$ rhizome length, 0.28$)$.

Swedish genets, differences between sites were more homogeneous; no significant variation in shoot length was detected for the Scottish genets.

Ramet production increased at experimental sites from north to south (ANOVA, $P<10^{-12}$; Fig. 2B), while shoot-to-root ratio tended to be lower at the Norwegian site (ANOVA, $P<10^{-4}$; data not shown). Variation among regions of origin was correlated for both variables. Scottish and Dutch/English genets showed the largest plasticity in ramet production (Fig. 2B) and lowest plasticity in shoot-to-root ratio. Russian, Swedish, and mediterranean genets showed larger plasticity in shoot-to-root ratio and a narrower plastic range in ramet production (Fig. 2B).

Seed production was very low. Only mediterranean genets growing in Spain set fruit (2 out of 16 genets). On average, $14 \%$ of all mediterranean plants growing in Spain produced seeds.

Plant survival varied significantly among sites, and among the regions and populations where the genets originated (ANOVA, $P=0.0019, P=0.0015$, and $P$ $=0.023$, respectively). However, none of the interactions with experimental site was significant, i.e., genetic and environmental effects on survival were ad- 
ditive. Survival was significantly lower in Norway than in the Netherlands and Spain $(P<0.003$, Scheffé post hoc tests), which did not differ significantly $(P=0.44)$. The mediterranean genets showed a significantly lower survival than all other genets $\left(P<10^{-7}\right.$ for all Scheffé post hoc comparisons involving the mediterranean genets), which did not differ significantly among themselves $(P>0.18$; data not shown). The type of propagule from which the plants grew had no significant effect on survival. Irrespective of type, propagule size was, on the other hand, positively correlated with survival (ANOVA, $P=0.007$ for tubers, $P<10^{-5}$ for rhizomes).

Selection coefficients varied significantly among sites and among the populations where the genets originated (ANOVA, $P=0.0007$ and $P=0.008$, respectively) and were significantly affected by the site $\times$ region interaction (ANOVA, $P=0.0012$ ). At all experimental sites, midlatitude genets (i.e., those from Scotland and Netherlands/England) had the highest fitness, while those from the mediterranean and Swedish regions had the lowest (Table 1 ). Russian genets had intermediate fitness in Spain and The Netherlands and higher fitness, though not significantly different from the midlatitude genets, in the Norwegian site (Table 1 ).

\section{DISCUSSION}

Our results show that most $P$. pectinatus genets can grow and reproduce asexually at distant latitudes. Subarctic and temperate genets grew and produced tubers at the three experimental sites (Norway, The Netherlands, and Spain). For all genets, independent of the region and population of origin, biomass yield and tuber production increased when grown at decreasing latitude. This might suggest that, in Europe, optimal conditions for growth of $P$. pectinatus are encountered in the mediterranean region. It should be noted, however, that habitat availability in that region is limited by the scarcity of permanent waterbodies (since most shallow lakes dry up during the summer) or by major fluctuations in water depth (Gafny and Gasith 1999). Hence, $P$. pectinatus is most abundant at middle latitudes in Europe (Hultén and Fries 1986), although the potential for clonal growth and multiplication is higher in the south (see also Yeo 1965).

Tuber production was highest for the midlatitude genets, i.e., those from The Netherlands and the UK $\left(52-56^{\circ} \mathrm{N}\right)$, irrespective of the experimental site where they were grown. The second component of survivorship, plant survival during the growth season, did not vary significantly among nonmediterranean genets. Selection coefficients thus indicated that populations from middle latitudes perform better at all sites. Local adaptation seems to play a minor role in the phenotypic performance of these plants. Our results are more in agreement with the observation that range-marginal populations show decreased fitness due to genetic processes, such as genetic drift, inbreeding, and low ge- notypic diversity associated with small population size and reduced sexual reproduction (Lesica and Allendorf 1995, Jonas and Geber 1999, Kark 1999, García et al. 2000, Dorken and Eckert 2001; but see Sagarin and Gaines 2002). It is noteworthy that a different component of asexual fitness, ramet production, shows a comparable pattern of variation among genets.

However, in our high-latitude experimental site (Norway), Russian genets showed their maximum fitness, although not significantly higher than the Dutch and Scottish genets. For the Russian genets, marginal changes in survival seem to compensate for the decreased tuber production when growing under the limiting conditions typical of cold-temperate and subarctic sites. Our results are consistent with common-garden experiments demonstrating that high-latitude populations of $P$. pectinatus complete their life cycle and produce tubers earlier (Pilon et al. 2002). Compressed life cycles are generally predicted to increase survival in the north, where summers are short and the conditions in late spring and early autumn are unpredictable, but at the cost of reduced plant growth and propagule size when growing in more favorable environments.

Mediterranean genets failed to produce tubers by mid-September at the three experimental sites. Although they had a biomass yield comparable to all other genets, except the Russian, they had a higher proportion of nonsenescent biomass and much thicker rhizomes at harvest. In the temperate and subarctic region, surviving without tubers (i.e., as a perennial) is rarely possible owing to the severe winters with their drastically reduced day lengths, low water temperatures, and frequent frost damage in shallow areas; hence, mediterranean genets would not be able to establish. In mediterranean climates, on the other hand, with their extended spring-autumn growth seasons and mild winters, perenniality and/or delayed tuberization are likely to result in increased competitive ability.

Hence, mediterranean genets seem to be locally adapted: owing to their perennial life cycle, they would be unable to become established in temperate to subarctic populations, but they may have a competitive advantage in climates with mild winters. Correlated changes in shoot length, shoot-to-root ratio, and tuber size are consistent with this hypothesis. Shoot length increased with decreasing latitude of origin of the genets. Early elongation of shoot internodes is a wellknown response to shading, and high plasticity in this trait confers an advantage in environments when competition for light is a significant selection factor (e.g., Dudley and Schmitt 1995, Schmitt et al. 1995). In southern sites, characterized by high population densities and high biomass standing crop (due to the mild winters and better growth conditions during springsummer; L. Santamaría, personal observation), this trait will probably confer a competitive advantage to the local genets. Mediterranean genets showed greater plasticity in shoot-to-root ratio (a trait also involved in 
light-competition responses) than the midlatitude genets, and they produced larger tubers, which are known to confer a competitive advantage in dense populations (Spencer and Ksander 1995). It is however remarkable that the Swedish genets showed a similar pattern of variation. Until more information becomes available on the relative contribution of tuber size and shoot-toroot allocation to competition and plant survival under different climatic regimes, it is difficult to interpret these traits more accurately.

Our data thus seem to point to two contrasting situations. On the one hand, variation in life-history traits and fitness estimates suggests that genets originating from temperate, midlatitude regions have general purpose genotypes that are able to grow optimally at very distant latitudes. On the other hand, range limit populations show changes in their life history (compressed life cycles in the north, true perenniality in the south) that may allow them to perform better locally. This discrepancy may be caused by limitations in the duration of our experiment, which does not allow for long-term estimates of fitness (over several clonal generations) that would take into account variable life histories among different genets. Alternatively, we may be looking at the spatial overlap of two different processes. Local adaptation may be constrained, but still arise among populations showing center-periphery gradients in plant performance due to genetic effects (as described previously). Under such circumstances, the likelihood of finding observable effects reflecting local adaptation, i.e., home vs. away advantages, will be highest in experimental manipulations over large geographic areas and strong environmental gradients, particularly those covering the full gradient between both distributional range limits in broadly distributed species (as we did here).

\section{ACKNOWLEDGMENTS}

Thanks are due to C.M. Herrera, I. Gómez Mestre, M.A. Rodríguez Gironés, and two anonymous referees for critically reviewing previous versions of the manuscript. Technical assistance by L. Arjona, E. Casado, T. Dekkers, G. García, H. Korthals, T. Montras, E. Oeyvor Sahlqvist, M.A. Rodríquez Gironés, and C.B. Sánchez Prieto is gratefully acknowledged. During the course of a previous research project, L. Kautsky kindly provided tuber material from Ask $\varnothing$ Bay (Sweden) from which several clonal lines used here were derived. This research has been funded by the European Union Project 'LAKES: Long distance dispersal of aquatic key species' (ENV4-CT97-0585). This is publication no. 0000 of the Netherlands Institute of Ecology, Center for Limnology and publication no. 000 of the Center for Wetland Ecology.

\section{Literature Cited}

Aizen, M. A., and H. Woodcock. 1992. Latitudinal trends in acorn size in eastern North American species of Quercus. Canadian Journal of Botany 70:1218-1222.

Barrett, S. C. H., C. G. Echert, and B. C. Husband. 1993. Evolutionary processes in aquatic plant populations. Aquatic Botany 44:105-145.

Berry, J. A., and J. K. Raison. 1981. Responses of macrophytes to temperature. Pages 277-337 in O. L. Lange, P. S. Nobel, C. B. Osmond, and H. Ziegler, editors. Physio- logical plant ecology I. Responses to the physical environment. Springer-Verlag, New York, New York, USA.

Björkman, O. 1981. Responses to different quantum flux differences. Pages 57-107 in O. L. Lange, P. S. Nobel, C. B. Osmond, and H. Ziegler, editors. Physiological plant ecology I. Responses to the physical environment. SpringerVerlag, New York, New York, USA.

Bradshaw, A. D. 1984. Ecological significance of genetic variation between populations. Pages 213-228 in R. Dirzo and J. Sarukhán, editors. Perspectives in plant population ecology. Sinauer Associates, Sunderland, Massachusetts, USA.

Carpenter, S. R., and D. M. Lodge. 1986. Effects of submersed macrophytes on ecosystem processes. Aquatic Botany 26:341-370.

Chapin, F. S., III, and M. C. Chapin. 1981. Ecotypic differentiation of growth processes in Carex aquatilis along latitudinal and local gradients. Ecology 62:1000-1009.

Crone, E. E. 2001. Is survivorship a better fitness surrogate than fecundity? Evolution 55:2611-2614.

DeWitt, T. J., A. Sih, and D. S. Willson. 1998. Costs and limits of phenotypic plasticity. Trends in Ecology and Evolution 13:77-81.

Dorken, M. E., and C. G. Eckert. 2001. Severely reduced sexual reproduction in northern populations of a clonal plant, Decodon verticillatus (Lythraceae). Journal of Ecology 89:339-350.

Dudley, S. A., and J. Schmitt. 1995. Genetic differentiation in morphological responses to simulated foliage shade between populations of Impatiens capensis from open and woodland sites. Functional Ecology 9:655-666.

Gafny, S., and A. Gasith. 1999. Spatially and temporally sporadic appearance of macrophytes in the littoral zone of Lake Kinneret, Israel: taking advantage of a window of opportunity. Aquatic Botany 62:249-267.

García, D., R. Zamora, J. M. Gómez, P. Jordano, and J. A. Hódar. 2000. Geographical variation in seed production, predation and abortion in Juniperus communis throughout its range in Europe. Journal of Ecology 88:436-446.

Hultén, E., and M. Fries. 1986. Atlas of North European vascular plants: north of the Tropic of Cancer. Koeltz Scientific Books, Königstein, Germany.

Jonas, C. S., and M. A. Geber. 1999. Variation among populations of Clarkia unguiculata (Onagraceae) along altitudinal and latitudinal gradients. American Journal of Botany 86:333-343.

Joshi, J., et al. 2001. Local adaptation enhances performance of common plant species. Ecology Letters 4:536-544.

Kark, S. 1999. Within-population diversity in the distribution range: partridges as a research model. PhD Thesis. Hebrew University of Jerusalem, Jerusalem, Israel.

King, R. A., R. J. Gornall, C. D. Preston, and J. M. Croft. 2001. Molecular confirmation of Potamogeton $\times$ bottnicus (P. pectinatus $\times P$. vaginatus, Potamogetonaceae) in Britain. Botanical Journal of the Linnean Society 135:67-70.

Koch, E. W., and C. J. Dawes. 1991. Ecotypic differentiation in populations of Ruppia maritima L. germinated from seeds and cultured under algae-free laboratory conditions. Journal of Experimental Marine Biology and Ecology 152: $145-159$.

Lesica, P., and F. W. Allendorf. 1995. When are populations valuable for conservation? Conservation Biology 9:753-760.

Li, B., J. Suzuki, and T. Hara. 1998. Latitudinal variation in plant size and relative growth rate in Arabidopsis thaliana. Oecologia 115:293-301.

Linhart, Y. B., and M. C. Grant. 1996. Evolutionary significance of local genetic differentiation in plants. Annual Review of Ecology and Systematics 27:237-277.

McGraw, J. B., and J. Antonovics. 1983. Experimental ecology of Dryas octopetala ecotypes. I. Ecotypic differenti- 
ation and life-cycle stages of selection. Journal of Ecology 71:879-897.

Nagy, E. S., and K. J. Rice. 1997. Local adaptation in two subspecies of an annual plant: implications for migration and gene flow. Evolution 51:1079-1089.

Orfanidis, S., and A. M. Breeman. 1999. Geographic variation in thermal traits in Digenea simplex and Champia parvula (Rhodophyta) in relation to present and glacial temperature regimes. Journal of Phycology 35:919-930.

Phillips, R. C., C. McMillan, and K. W. Bridges. 1983. Phenology of eelgrass Zostera marina L., along latitudinal gradients in North America. Aquatic Botany 15:145-156.

Pilon, J. J., L. Santamaría, M. J. M. Hootsmans, and W. van Vierssen. 2002. Latitudinal variation in life-cycle characteristics of Potamogeton pectinatus L.: vegetative growth and asexual reproduction. Plant Ecology 165:247-262.

Potvin, C. 1986. Biomass allocation and phenological differentiation amongst southern and northern populations of the $\mathrm{C}_{4}$ grass Echinocloa crus-galli. Journal of Ecology 74: 915-923.

Preston, C. D., P. M. Hollingworth, and R. J. Gornall. 1998. Potamogeton pectinatus $\mathrm{L} . \times P$. vaginatus Turcz. $(P . \times$ bottnicus Hagstr.), a newly identified hybrid in the British Isles. Watsonia 22:69-82.

Preston, C. D., P. M. Hollingworth, and R. J. Gornall. 1999. The distribution and habitat of Potamogeton $\times$ suecicus $\mathrm{K}$. Richt. (P. filiformis Pers. $\times P$. pectinatus L.) in the British Isles. Watsonia 22:329-342.

Rossiter, M. C. 1998. The role of environmental variation in parental effects expression. Pages 112-133 in T. A. Mousseau and C. W. Fox, editors. Maternal effects as adaptations. Oxford University Press, New York, New York USA.

Sagarin, R. D., and S. D. Gaines. 2002. The 'abundant centre' distribution: to what extent is it a biogeographical rule? Ecology Letters 5:137-147.

Salisbury, F. B. 1981. Responses to photoperiod. Pages 135168 in O. L. Lange, P. S. Nobel, C. B. Osmond, and H. Ziegler, editors. Physiological plant ecology I. Responses to the physical environment. Springer-Verlag, New York, New York, USA.

Santamaría, L. 2002. Why are most aquatic plants broadly distributed? Dispersal, clonal growth and small-scale heterogeneity in a stressful environment. Acta Oecologica 23: $137-154$

Sawada, S., Y. Nakajima, M. Tsukuda, K. Sasaki, Y. Hazama, M. Futatsuya, and A. Watanabe. 1994. Ecotypic differ- entiation of dry matter production processes in relation to survivorship and reproductive potential in Plantago asiatica populations along climatic gradients. Functional Ecology 8:400-409.

Schlichting, C. D. 1986. The evolution of phenotypic plasticity in plants. Annual Review of Ecology and Systematics 17:667-693.

Schmid, B. 1985. Clonal growth in grassland perennials. III. Genetic variation and plasticity between and within populations of Bellis perennis and Prunella vulgaris. Journal of Ecology 73:819-830.

Schmitt, J., A. C. McCormac, and H. Smith. 1995. A test of the adaptive plasticity hypothesis using transgenic and mutant plants disabled in phytochrome-mediated elongation responses to neighbors. American Naturalist 146:937-953.

Spencer, D. F., and G. G. Ksander. 1995. Influence of propagule size, soil fertility and photoperiod on growth and propagule production by three species of submersed macrophytes. Wetlands 15:134-140.

Statsoft. 1999. STATISTICA for Windows (computer program manual). Statsoft, Tulsa, Oklahoma, USA.

Van Tienderen, P. H. 1990. Morphological variation in Plantago lanceolata: limits of plasticity. Evolutionary Trends in Plants 4:35-43.

Van Wijk, R. J. 1989. Ecological studies on Potamogeton pectinatus L. 3. Reproductive strategies and germination ecology. Aquatic Botany 33:291-299.

Walter, H. 1973. Vegetation of the earth in relation to climate and the eco-physiological conditions. English Universities Press, London, UK.

Weber, E., and B. Schmid. 1998. Latitudinal population differentiation in two species of Solidago (Asteraceae) introduced into Europe. American Journal of Botany 85:1110-1121.

Winn, A. A., and K. L. Gross. 1993. Latitudinal variation in seed weight and flower number in Prunella vulgaris. Oecologia 93:55-62.

Woodward, F. I. 1990. The impact of low temperatures in controlling the geographical distribution of plants. Philosophical Transactions of the Royal Society of London Series $\mathrm{B}$ 326:585-593.

Woodward, F. I., and B. G. Williams. 1987. Climate and plant distribution at global and local scales. Vegetatio 69:189-197.

Yeo, R. R. 1965. Life history of sago pondweed. Weed Science 13:314-321.

\section{APPENDIX A}

A table presenting geographic characteristics of the populations and experimental sites is available in ESA's Electronic Data Archive: Ecological Archives E084-061-A1.

\section{APPENDIX B}

Intersimple sequence repeat "fingerprinting" method is available in ESA's Electronic Data Archive: Ecological Archives E084-061-A2.

\section{APPENDIX C}

Plant cultivation methods are available in ESA's Electronic Data Archive: Ecological Archives E084-061-A3.

APPENDIX D

Statistical methods are available in ESA's Electronic Data Archive: Ecological Archives E084-061-A4.

\section{APPENDIX E}

Results of mixed-model General Linear Modeling are available in ESA's Electronic Data Archive: Ecological Archives E084-061-A5. 